\title{
Erratum to: On the relationship between ozone and its precursors in the Pearl River Delta: application of an observation-based model (OBM)
}

Hairong Cheng $\cdot$ Hai Guo $\cdot$ Xinming Wang .

Sam M. Saunders $\cdot$ S. H. M. Lam • Fei Jiang •

Tijian Wang • Aijun Ding $\cdot$ Shuncheng Lee $\cdot$ K. F. Ho

Published online: 16 June 2010

(C) Springer-Verlag 2010

Erratum to: Environ Sci Pollut Res

DOI 10.1007/s11356-009-0247-9

The original version of this article unfortunately contained a mistake. Two small figures were missed and a small figure was wrong in Fig. 4 on page 554. The correct Fig. 4 is as following:

The online version of the original article can be found at http://dx.doi. org/10.1007/s11356-009-0247-9.

H. Cheng $\cdot$ H. Guo $(\bowtie) \cdot$ A. Ding $\cdot$ S. Lee $\cdot$ K. F. Ho

Department of Civil and Structural Engineering,

The Hong Kong Polytechnic University,

Kowloon, Hong Kong

e-mail: ceguohai@polyu.edu.hk

\section{Wang}

Guangzhou Institute of Geochemistry,

Chinese Academy of Sciences,

Guangzhou, China

S. M. Saunders $\cdot$ S. H. M. Lam

School of Biomedical, Biomolecular and Chemical Sciences,

University of Western Australia,

Perth, WA 6009, Australia

F. Jiang $\cdot$ T. Wang

Department of Atmospheric Sciences, Nanjing University,

Nanjing, China 
Fig. 4 Diurnal variations of $\mathrm{O}_{3}$, $\mathrm{NO}, \mathrm{CO}$, and TVOC on $\mathrm{O}_{3}$ episode days at WQS and TC
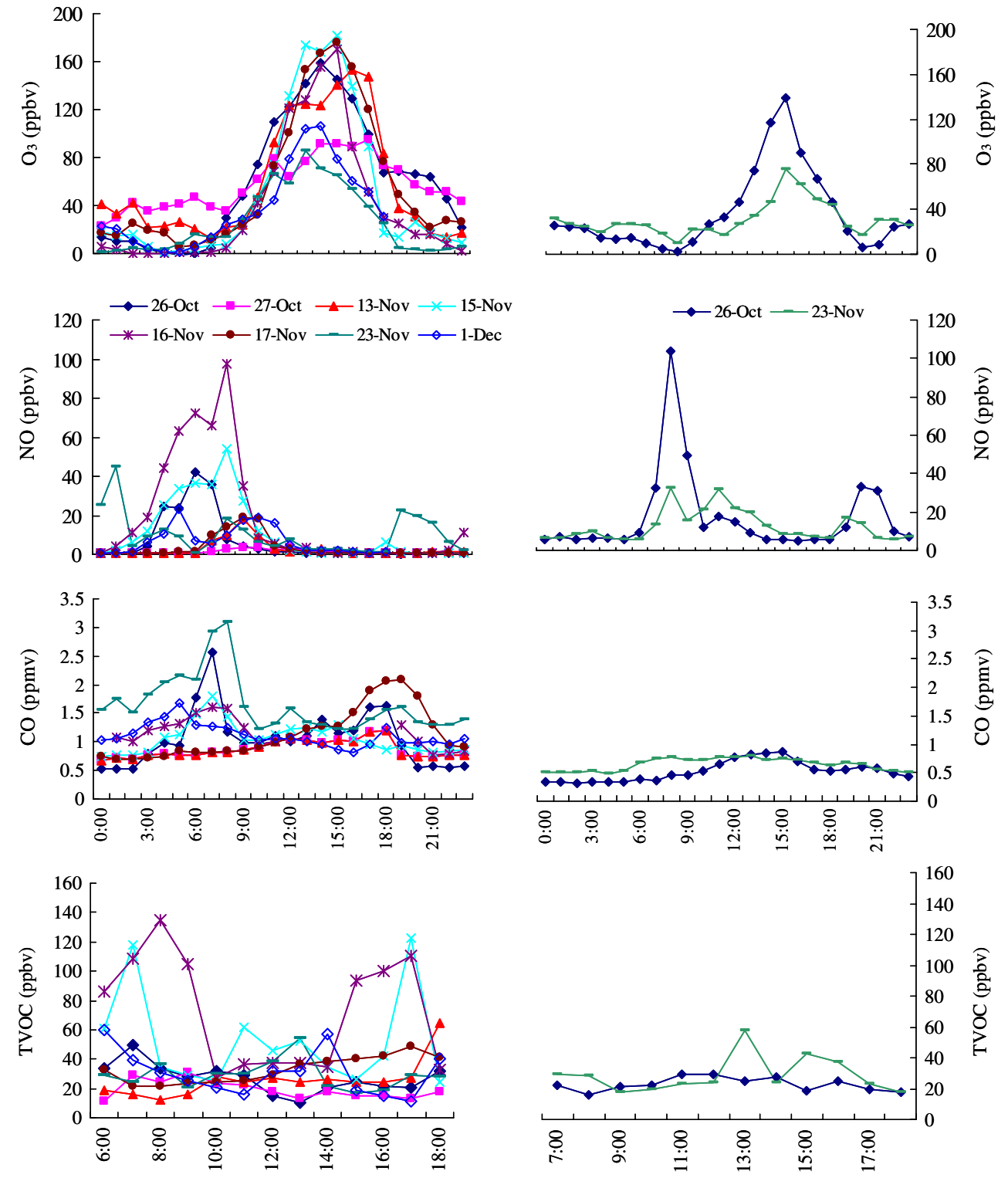